\title{
A Simple HPLC/DAD Method Validation for the Quantification of Malondialdehyde in Rodent's Brain
}

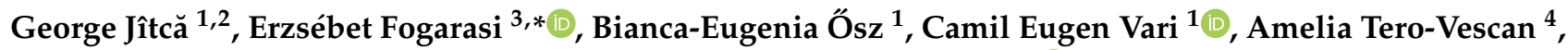 \\ Amalia Miklos ${ }^{4}$, Mădălina-Georgiana Bătrînu ${ }^{2}$, Carmen Maria Rusz ${ }^{5} \mathbb{D}^{\text {, }}$, Mircea Dumitru Croitoru ${ }^{3}$ \\ and Maria Titica Dogaru ${ }^{1}$
}

check for

updates

Citation: Jîtcă, G.; Fogarasi, E.; Ôsz, B.-E.; Vari, C.E.; Tero-Vescan, A.; Miklos, A.; Bătrînu, M.-G.; Rusz, C.M.; Croitoru, M.D.; Dogaru, M.T. A Simple HPLC/DAD Method Validation for the Quantification of Malondialdehyde in Rodent's Brain. Molecules 2021, 26, 5066. https:// doi.org/10.3390/molecules26165066

Academic Editor: Andreas Tzakos

Received: 28 July 2021

Accepted: 19 August 2021

Published: 21 August 2021

Publisher's Note: MDPI stays neutral with regard to jurisdictional claims in published maps and institutional affiliations.

Copyright: (C) 2021 by the authors. Licensee MDPI, Basel, Switzerland. This article is an open access article distributed under the terms and conditions of the Creative Commons Attribution (CC BY) license (https:// creativecommons.org/licenses/by/ $4.0 /)$.
1 Department of Pharmacology and Clinical Pharmacy, Faculty of Pharmacy, George Emil Palade University of Medicine, Pharmacy, Science and Technology of Târgu Mureș, 540139 Târgu Mureș, Romania; george.jitca@umfst.ro (G.J.); bianca.osz@umfst.ro (B.-E.Ö.); camil.vari@umfst.ro (C.E.V.); maria_dogaru2004@yahoo.com (M.T.D.)

2 Doctoral School of Medicine and Pharmacy, I.O.S.U.D., George Emil Palade University of Medicine, Pharmacy, Science and Technology of Târgu Mureș, 540139 Târgu Mureș, Romania; batrinumadalina@yahoo.com

3 Department of Toxicology and Biopharmacy, Faculty of Pharmacy, George Emil Palade University of Medicine, Pharmacy, Science and Technology of Târgu Mureș, 540139 Târgu Mureș, Romania; mircea.croitoru@umfst.ro

4 Department of Biochemistry, Faculty of Pharmacy, George Emil Palade University of Medicine, Pharmacy, Science and Technology of Târgu Mureș, 540139 Târgu Mureș, Romania; amelia.tero-vescan@umfst.ro (A.T.-V.); amalia.miklos@umfst.ro (A.M.)

5 Faculty of Pharmacy, George Emil Palade University of Medicine, Pharmacy, Science and Technology of Târgu Mureș, 540139 Târgu Mureș, Romania; carmenrusz20@gmail.com

* Correspondence: erzsebet.fogarasi@umfst.ro

Abstract: In the present study, a HPLC/DAD method was set up to allow for the determination and quantification of malondialdehyde (MDA) in the brain of rodents (rats). Chromatographic separation was achieved on Supelcosil LC-18 $(3 \mu \mathrm{m})$ SUPELCO Column $3.3 \mathrm{~cm} \times 4.6 \mathrm{~mm}$ and Supelco Column Saver $0.5 \mu \mathrm{m}$ filter by using a mobile phase acetonitrile (A) and phosphate buffer $(20 \mathrm{mM}, \mathrm{pH}=6)$ (B). Isocratic elution was $14 \%$ for (A) and $86 \%$ for (B). The injection volume (loop mode) was $100 \mu \mathrm{L}$ with an analysis time of $1.5 \mathrm{~min}$. Flow rate was set at $1 \mathrm{~mL} / \mathrm{min}$. The eluted compound was detected at $532 \mathrm{~nm}$ by a DAD detector by keeping the column oven at room temperature. The results indicated that the method has good linearity in the range of $0.2-20 \mu \mathrm{g} / \mathrm{g}$. Both intra- and inter-day precision, expressed as RSD, were $\leq 15 \%$ and the accuracies ranged between $\pm 15 \%$. The lower limit of quantification (LLOQ), stability, and robustness were evaluated and satisfied the validation criteria. The method was successfully applied in a study of chronic toxicology following different treatment regimens with haloperidol and metformin.

Keywords: oxidative stress; malondialdehyde; brain; liquid chromatography; diode array detector

\section{Introduction}

Oxidative stress is currently one of the most intensely studied processes. It appears when reactive oxygen species (ROS) and reactive nitrogen species (RNS) production exceeds the neutralizing capacity of endogenous antioxidant systems [1,2]. Mitochondrial impairment constitutes a crucial and critical factor in the aging process and development of age-related disorders and is generally accepted. This impairment occurs due to the loss of oxidative phosphorylation capacity and oxygen radical leakage, with the subsequent apparition of ROS. These reactive species can constitute either physiological signals (low levels) or toxic species (high levels) that affect cellular integrity, depending on the concentration $[3,4]$. One of the most studied reactions involved in the oxidative stress is lipid peroxidation, thus the increased reactivity of these ROS and RNS makes all biological structures susceptible to oxidative processes, particularly the brain [5], due to its high 
lipid content [6]. Lipid peroxidation reactions affect the cellular membrane, degrading it, and subsequently, degradation products are obtained, i.e., malondialdehyde (MDA) [7,8], which can propagate and amplify the oxidative lesions. Compared to other degradation compounds, MDA is obtained in high quantities and is considered a marker of oxidative stress $[9,10]$. MDA's property of cross-linking other molecules contributes to its toxic potential, at the same time, the mutagenic and carcinogenic effects are attributed to the chemical bonds that MDA forms with the nitrogen bases from the nucleic acid structure [11].

Increased levels of MDA in the brain have been observed in central nervous system (CNS) disorders [3,12,13], such as Alzheimer's disease [14], Parkinson's disease [15], or in cases of consumption or abuse of drugs [16]. A widely known and used method of MDA assay is the spectrophotometric method in which a pink colored complex is obtained (MDA-TBA) from the MDA reaction with thiobarbituric acid (TBA) under high temperature and low $\mathrm{pH}$, as shown in Figure 1.
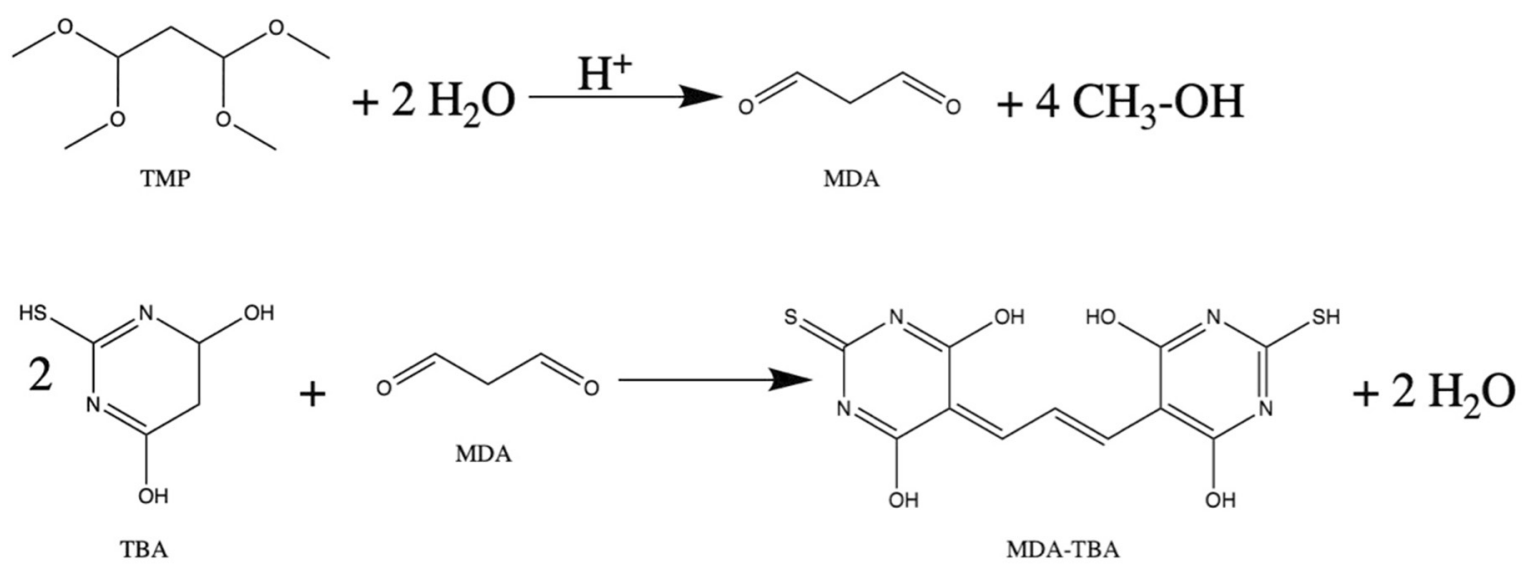

Figure 1. Reaction of generative malondialdehyde (MDA) from 1,1,3,3-Tetramethoxypropane (TMP) and the colored pink product resulted from the reaction between thiobarbituric acid (TBA) and MDA.

Despite attempts of optimization of this method, spectrophotometric determination still has limitations due to TBA that can interact with other compounds such as carbohydrates, amino acids, and certain pigments, resulting in higher values $[17,18]$ that are undesirable, especially in human tissue determinations in which more specific methods are required [19]. Thus, in an attempt to avoid the bias of the TBA interaction with other molecules and with the purpose of obtaining MDA values as close as possible to the real values, the present paper aims to validate a method of identifying MDA in the brain. Separation of the analytes was obtained using a high-performance liquid chromatographic (HPLC) system coupled with a diode array detector (HPLC/DAD). This technique overcomes the limitations of the spectrophotometric method in terms of specificity and sensitivity, being a simple, fast, and cost-effective method.

\section{Results and Discussion}

\subsection{Method Validation}

\subsubsection{Optimization of Sample Preparation}

In order to be as accurate as possible, three methods of sample preparation were tested. In the first method, we used an automatic homogenizer IKA Ultra-Turrax Tube Drive. For the second method, manual trituration of the sample in mortar with pestle was used in the presence of silicon dioxide. The third method combined the above-mentioned methods. Comparing the areas of the peaks obtained by the three processing methods, the following values were obtained: the mean of the three obtained areas under the curve (AUC), 65538.33; standard deviation (SD), 7584.11; and relative standard deviation (RSD\%), 11.57. No major differences were observed between the three methods used, in terms of 
areas. In order to avoid unnecessary prolongation of processing, the automated method was used with the IKA Ultra-Turrax Tube Drive.

\subsubsection{Chromatographic Conditions}

For MDA analysis, chromatographic separation was performed using a mobile phase acetonitrile $(\mathrm{A})$ and phosphate buffer $(20 \mathrm{mM}, \mathrm{pH}=6)(\mathrm{B})$. Isocratic elution was $14 \%$ for (A), $86 \%$ for (B). The injection volume (loop mode) was $100 \mu \mathrm{L}$ with an analysis time of $1.5 \mathrm{~min}$. Flow rate was set at $1 \mathrm{~mL} / \mathrm{min}$, eluent was monitored with a DAD, and the best chromatogram achieved was at $532 \mathrm{~nm}$, using Supelcosil LC-18 (3 $\mu \mathrm{m})$ SUPELCO Column $3.3 \mathrm{~cm} \times 4.6 \mathrm{~mm}$ and Supelco Column Saver $0.5 \mu \mathrm{m}$ filter [20].

\subsubsection{Linearity and LLOQ}

The linearity of the method was verified through the analytical curve using six levels of concentrations, evaluated in triplicates. The analytical curve was described by the linear equation: $y=21,749 x-8928.3$ while the regression coefficient was $r^{2}=0.998$, as illustrated in Figure 2, where $y$ is the analyte peak area ratio and $x$ is the concentration $(\mu \mathrm{g} / \mathrm{g})$ as shown in Table 1.

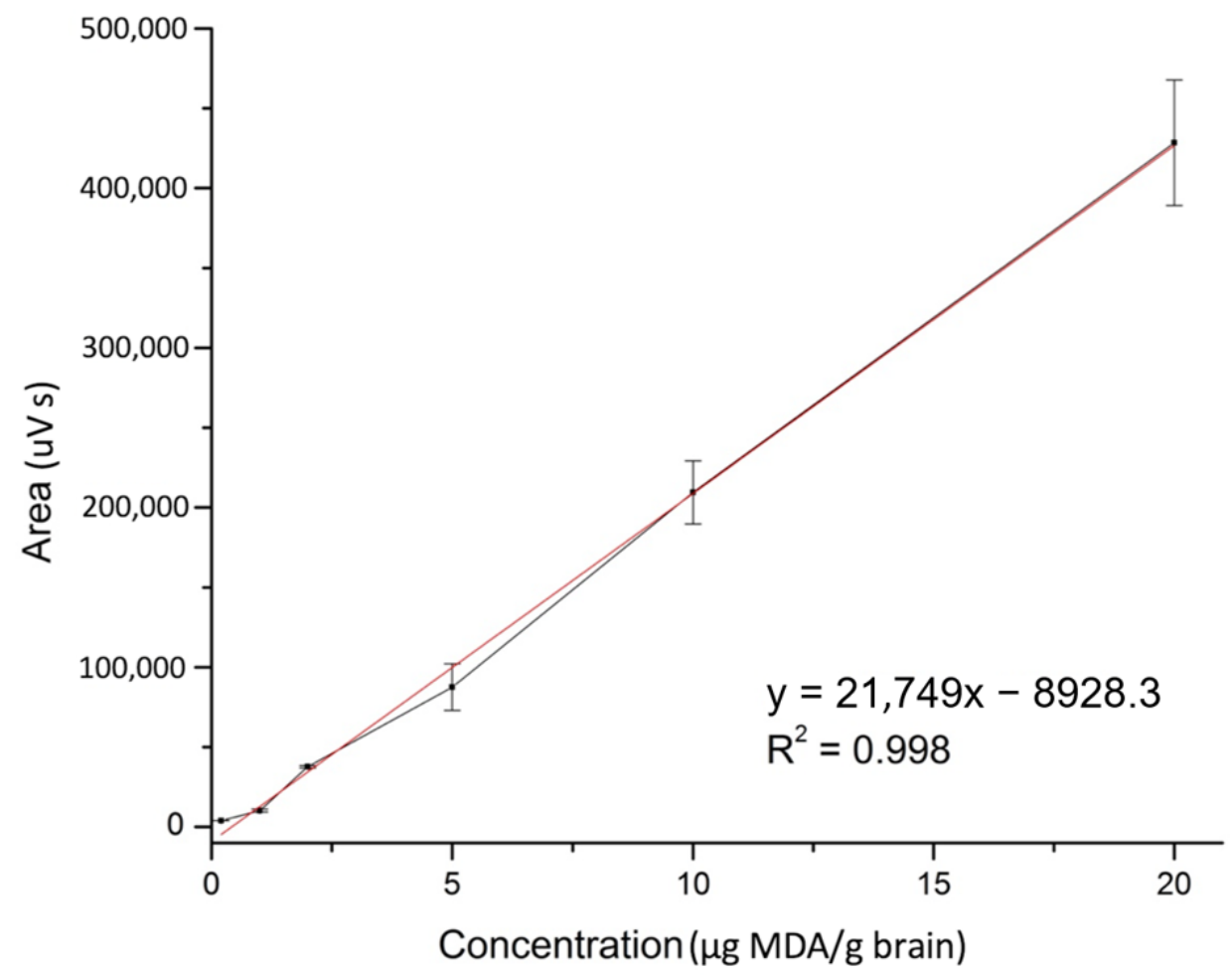

Figure 2. Analytical curve of the HPLC/DAD assay of malondialdehyde (MDA) in the range of $0.20-20 \mu \mathrm{g} / \mathrm{g}$ brain, with line equation $\mathrm{y}=21,749 \mathrm{x}-8928.3$.

\subsubsection{Selectivity}

The selectivity of the method in terms of its ability to accurately measure the analyte of interest in the presence of other components that were present in the sample matrix was demonstrated by the analysis of blank matrices. To verify the selectivity, we injected three blank samples prepared according to the sample preparation procedure described in Section 3.3. Sample preparation with the following modification: TBA without MDA, MDA without TBA, and brain sample without TBA in which the reagent was replaced with purified water. After injecting these blank samples in neither one of these cases, interferences did not occur at the retention time of $1.1 \mathrm{~min}$. The peak purity in all cases was above $98.7 \%$. 
Table 1. Analytical factors of the HPLC method.

\begin{tabular}{cc}
\hline Analytical Factor & MDA \\
\hline LLOQ $(\mu \mathrm{g} / \mathrm{g}$ brain) & 0.20 \\
rLLOQ $(\%)$ & 94.91 \\
LLOQrec $(\mu \mathrm{g} / \mathrm{g}$ brain) & 0.20 \\
rLLOQrec $(\%)$ & 104.97 \\
Slope & 21,749 \\
Y-intercept & 8928.30 \\
Determination coefficient $\left(\mathrm{r}^{2}\right)$ & 0.998 \\
Analytical range ( $\mu$ g/g brain) & $0.20-20$ \\
Retention time (min) & $1.11 \pm 0.01$ \\
\hline rLLOQ, relative lower limit of quantification; LLOQrec, recovery-corrected LLOQ; rLLOQrec (\%), relative \\
recovery-corrected LLOQ.
\end{tabular}

\subsubsection{Accuracy}

Quality control (QC) samples at lower limit of quantification (LLOQ) concentration and three different concentration levels (low, medium, and high) were spiked for the determination of precision and accuracy. Five replicates for each level of QC samples were assayed in one run for the intra-day procedure.

The accuracy was evaluated based on the percentage of MDA recovered from the brain matrix. Representative chromatogram of MDA is illustrated in Figure 3. Data for the intra- and inter-day accuracy for MDA at LLOQ and three QC levels are illustrated in Table 2.

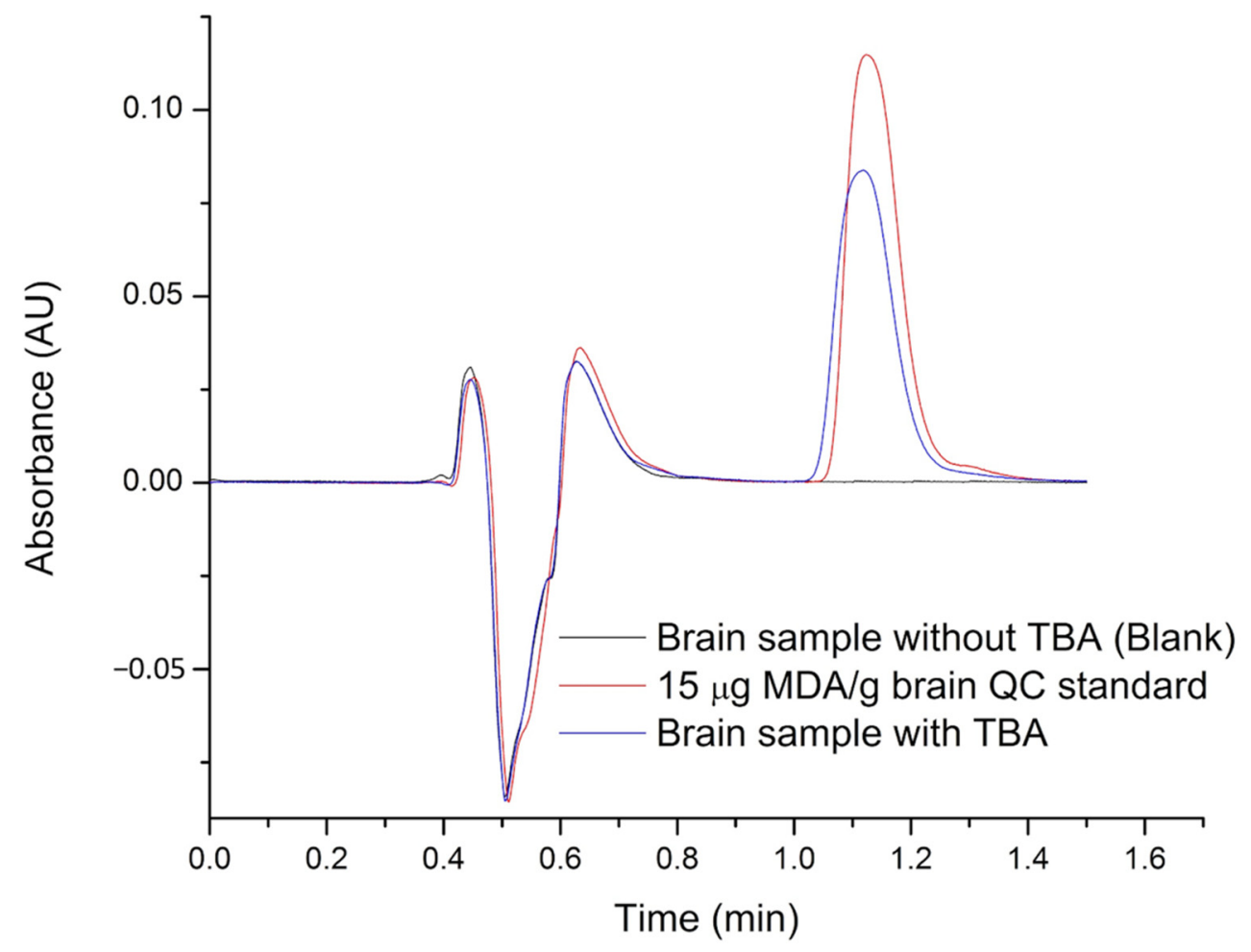

Figure 3. Representative chromatogram of a rat brain sample spiked. Analysis conditions: mobile phase (1 $\mathrm{mL} / \mathrm{min})$, acetonitrile: phosphate buffer (14:86), C18 column, detection: DAD at $532 \mathrm{~nm}$, room temperature. 
Table 2. Precision and accuracy of malondialdehyde (MDA) in quality control samples.

\begin{tabular}{|c|c|c|c|c|c|c|c|c|c|}
\hline \multirow{2}{*}{\multicolumn{2}{|c|}{ Conc. ( $\mu \mathrm{g} / \mathrm{g}$ Brain) }} & \multicolumn{4}{|c|}{ Intra-Day } & \multicolumn{4}{|c|}{ Inter-Day } \\
\hline & & Mean & SD & RSD \% & Accuracy \% & Mean & SD & RSD \% & Accuracy \% \\
\hline \multirow{4}{*}{ MDA } & 0.2 & 0.18 & 0.03 & 15.30 & 90.42 & 0.17 & 0.02 & 14.30 & 83.88 \\
\hline & 0.5 & 0.49 & 0.06 & 13.02 & 98.18 & 0.50 & 0.06 & 11.17 & 99.08 \\
\hline & 7.5 & 6.90 & 0.52 & 7.52 & 91.99 & 7.00 & 0.43 & 6.20 & 93.40 \\
\hline & 15 & 15.36 & 0.67 & 4.39 & 102.38 & 15.10 & 0.65 & 4.27 & 100.67 \\
\hline
\end{tabular}

\subsubsection{Precision}

Inter-day precision was evaluated on two different days using five replicates for each level of QC samples and at LLOQ concentration. Results of precision (intra-day and interday) were expressed as RSD\%. Data for the intra- and inter-day precision for MDA at LLOQ and three QC levels are illustrated in Table 2.

Both within run and between runs precision (RSD\%) of the QC samples were $\leq 15 \%$, and the accuracy ranged between $\pm 15 \%$. These results demonstrated that the method is reproducible for the determination of MDA in a rodent's brain as the results demonstrated that the precision and accuracy are in acceptable limits.

\subsubsection{Stability}

The stability was analyzed by assaying the frozen $\left(-80^{\circ} \mathrm{C}\right) \mathrm{QC}$ samples with the $\mathrm{QC}$ samples kept at $25^{\circ} \mathrm{C}$ for $24 \mathrm{~h}$ and for $48 \mathrm{~h}$, both in triplicates. Analytical recovery varied between $106.69-115.79 \%$ after $24 \mathrm{~h}$ and between $100.45-114.05 \%$ after $48 \mathrm{~h}$ at $-80{ }^{\circ} \mathrm{C}$. For the samples that have been kept under room temperature, the recovery varied between $98.09-109.06 \%$ after $24 \mathrm{~h}$ and between $93.26-110.96 \%$ after $48 \mathrm{~h}$. The data are listed in Table 3.

Table 3. Stability assessment for samples stored at $-80^{\circ} \mathrm{C}$ and at room temperature for 24 and $48 \mathrm{~h}$, respectively.

\begin{tabular}{|c|c|c|c|c|c|c|c|c|c|c|c|c|c|}
\hline \multirow{3}{*}{\multicolumn{2}{|c|}{ Parameters }} & \multicolumn{6}{|c|}{ Stability for Stored Samples at $-80{ }^{\circ} \mathrm{C}$} & \multicolumn{6}{|c|}{ Stability for Samples Stored at Room Temperature } \\
\hline & & \multicolumn{6}{|c|}{ Conc. $(\mu \mathrm{g} / \mathrm{g}$ Brain) } & \multicolumn{6}{|c|}{ Conc. ( $\mu g / g$ Brain) } \\
\hline & & \multicolumn{2}{|c|}{0.5} & \multicolumn{2}{|c|}{7.5} & \multicolumn{2}{|c|}{15} & \multicolumn{2}{|c|}{0.5} & \multicolumn{2}{|c|}{7.5} & \multicolumn{2}{|c|}{15} \\
\hline & & $24 \mathrm{~h}$ & $48 \mathrm{~h}$ & $24 \mathrm{~h}$ & $48 \mathrm{~h}$ & $24 \mathrm{~h}$ & $48 \mathrm{~h}$ & $24 \mathrm{~h}$ & $48 \mathrm{~h}$ & $24 \mathrm{~h}$ & $48 \mathrm{~h}$ & $24 \mathrm{~h}$ & $48 \mathrm{~h}$ \\
\hline \multirow{4}{*}{ MDA } & Mean & 0.52 & 0.55 & 7.98 & 7.55 & 16.76 & 15.42 & 0.53 & 0.54 & 7.15 & 6.43 & 15.06 & 14.67 \\
\hline & $\operatorname{Rec} *, \%$ & 106.69 & 114.05 & 115.79 & 109.49 & 109.15 & 100.45 & 109.06 & 110.96 & 103.71 & 93.26 & 98.09 & 95.58 \\
\hline & SD & 0.08 & 0.06 & 0.06 & 0.13 & 0.52 & 0.54 & 0.05 & 0.07 & 0.74 & 0.31 & 0.67 & 0.90 \\
\hline & RSD \% & 3.56 & 2.63 & 0.60 & 1.44 & 2.78 & 3.16 & 1.99 & 2.76 & 8.19 & 3.70 & 3.97 & 5.43 \\
\hline
\end{tabular}

\subsubsection{Robustness}

The robustness of the method was assessed with the performance of variations in three crucial chromatographic parameters (mobile phase ratio, $\mathrm{pH}$ value of mobile phase, and flow rate). All assays were performed at a concentration level of $0.5,7.5$, and $15 \mu \mathrm{g} / \mathrm{g}$ for MDA, in five replicates. All the data are listed in Table 4. Changes in retention times as a function of variation of the chromatographic parameter are illustrated in Figure 4. 
Table 4. Robustness of the method by variation of three chromatographic parameters (mobile phase ratio, $\mathrm{pH}$ value of mobile phase, and flow rate).

\begin{tabular}{|c|c|c|c|c|}
\hline & Conc. ( $\mu g / g$ Brain) & Mean Area (mV S) \pm RSD, \% & Retention Time (min) \pm RSD, \% & Peak Purity $(\%) \pm$ RSD, $\%$ \\
\hline \multicolumn{5}{|c|}{ Mobile phase ratio $(v / v)$, acetonitrile: buffer $(\mathrm{pH} 6)$} \\
\hline \multirow{4}{*}{$84: 16$} & 0.5 & $11.18 \pm 0.58$ & $0.88 \pm 1.32$ & $97 \pm 1.57$ \\
\hline & 7.5 & $149.41 \pm 1.13$ & $0.87 \pm 0.66$ & $98 \pm 1.56$ \\
\hline & 15 & $304.56 \pm 1.44$ & $0.87 \pm 0.01$ & $99 \pm 0.59$ \\
\hline & 0.5 & $9.13 \pm 12.87$ & $1.12 \pm 0.52$ & $98 \pm 1.02$ \\
\hline \multirow[t]{2}{*}{$86: 14$} & 7.5 & $152.88 \pm 7.15$ & $1.11 \pm 0.90$ & $98 \pm 1.56$ \\
\hline & 15 & $332.64 \pm 3.56$ & $1.11 \pm 0.52$ & $97 \pm 1.19$ \\
\hline \multirow{3}{*}{$88: 12$} & 0.5 & $10.54 \pm 0.29$ & $1.44 \pm 0.40$ & $98+1.02$ \\
\hline & 7.5 & $164.09 \pm 0.97$ & $1.43 \pm 0.01$ & $98 \pm 1.56$ \\
\hline & 15 & $317.87 \pm 1.91$ & $1.43 \pm 0.01$ & $97 \pm 1.19$ \\
\hline \multicolumn{5}{|c|}{ Mobile phase pH value } \\
\hline \multirow{4}{*}{5.8} & 0.5 & $9.42 \pm 0.33$ & $1.09 \pm 0.92$ & $98 \pm 1.02$ \\
\hline & 7.5 & $157.13 \pm 1.42$ & $1.08 \pm 0.01$ & $96 \pm 1.59$ \\
\hline & 15 & $308.76 \pm 3.16$ & $1.08 \pm 0.66$ & $97 \pm 1.58$ \\
\hline & 0.5 & $9.13 \pm 12.87$ & $1.12 \pm 0.52$ & $98 \pm 1.02$ \\
\hline \multirow[t]{2}{*}{6} & 7.5 & $152.88 \pm 7.15$ & $1.11 \pm 0.90$ & $98 \pm 1.56$ \\
\hline & 15 & $332.64 \pm 3.56$ & $1.11 \pm 0.52$ & $97 \pm 1.19$ \\
\hline \multirow{3}{*}{6.2} & 0.5 & $9.63 \pm 1.11$ & $1.09 \pm 0.01$ & $98 \pm 1.17$ \\
\hline & 7.5 & $148.03 \pm 3.49$ & $1.10 \pm 1.33$ & $97 \pm 1.03$ \\
\hline & 15 & $303.40 \pm 0.16$ & $1.09 \pm 0.99$ & $97 \pm 1.57$ \\
\hline \multicolumn{5}{|c|}{ Flow rate $(\mathrm{mL} / \mathrm{min})$} \\
\hline \multirow{4}{*}{0.9} & 0.5 & $9.24 \pm 3.30$ & $1.63 \pm 0.35$ & $98 \pm 0.59$ \\
\hline & 7.5 & $173.82 \pm 2.29$ & $1.63 \pm 0.35$ & $97 \pm 1.57$ \\
\hline & 15 & $349.94 \pm 1.04$ & $1.64 \pm 0.35$ & $98 \pm 1.02$ \\
\hline & 0.5 & $9.13 \pm 12.87$ & $1.12 \pm 0.52$ & $98 \pm 1.02$ \\
\hline \multirow[t]{2}{*}{1.0} & 7.5 & $152.88 \pm 7.15$ & $1.11 \pm 0.90$ & $98 \pm 1.56$ \\
\hline & 15 & $332.64 \pm 3.56$ & $1.11 \pm 0.52$ & $97 \pm 1.19$ \\
\hline \multirow{3}{*}{1.1} & 0.5 & $9.80 \pm 2.49$ & $1.29 \pm 0.92$ & $98 \pm 0.59$ \\
\hline & 7.5 & $148.52 \pm 1.22$ & $1.28 \pm 0.01$ & $98 \pm 1.02$ \\
\hline & 15 & $293.04 \pm 1.34$ & $1.30 \pm 0.92$ & $98 \pm 0.59$ \\
\hline
\end{tabular}
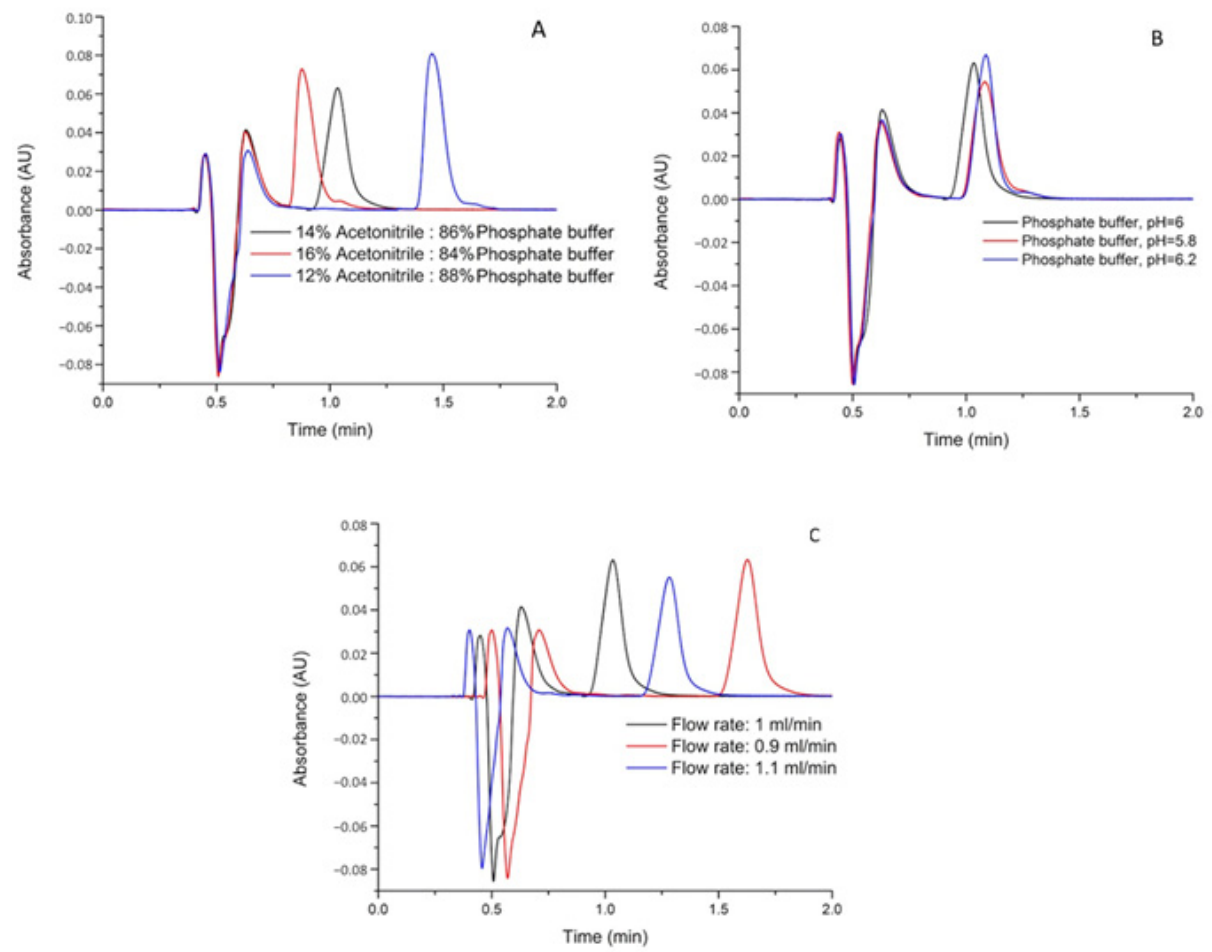

Figure 4. Changes of malondialdehyde (MDA) retention time depending on the variation of the chromatographic parameter $(\mathbf{A})$ represents the variation of the mobile phase composition; (B) represents the variation of the mobile phase $\mathrm{pH}$; and $(\mathbf{C})$ represents the variation of the mobile phase flow rate). 


\section{Materials and Methods}

\subsection{Chemical and Reagents}

All chemicals and reagents were analytically pure, and they were purchased from different providers: acetonitrile (VWR International, S.A.S., Fonteney-sous-Bois, France), anhydrous disodium phosphate $\left(\mathrm{Na}_{2} \mathrm{HPO}_{4}\right)$, and $85 \%$ phosphoric acid solution $\left(\mathrm{H}_{3} \mathrm{PO}_{4}\right)$ were purchased from Merck KGaA (Darmstadt, Germany). Thiobarbituric acid (98\%) and phosphate buffer solution (PBS) were purchased from Sigma-Aldrich (Darmstadt, Germany). Sulfuric acid solution $\left(\mathrm{H}_{2} \mathrm{SO}_{4}\right)(96 \%)$ was purchased from Chemical Company (Iasi, Romania). For the preparation of MDA standard solutions, 1,1,3,3-Tetramethoxypropane (TMP, 99\%, Sigma Aldrich, Shanghai, China) was used [21,22]. Ultra pure water was obtained using a Milli-Q purification system (Merck Millipore Corporation, Burlington, MA, USA).

\subsection{Preparation of Solutions}

For MDA stock solution was prepared by diluting $460 \mu \mathrm{L}$ of TMP in $100 \mathrm{~mL}$ ultra pure water; the concentration of this solution was equivalent to the MDA solution of $2 \mathrm{mg} / \mathrm{mL}$. Standard work solutions at 9 concentration levels were prepared by diluting stock solutions with ultra pure water. Six triplicate samples for linearity $(0.2-20 \mathrm{ug} / \mathrm{g}$ brain) and three QC samples were prepared at $0.5,7.5$, and $15 \mathrm{ug} / \mathrm{g}$ brain. For each QC sample, the analysis was performed in five replicates.

\subsection{Sample Preparation}

Twenty male rats weighing 450-500 g were individually housed in plastic cages, maintained on a 12:12 h light-dark cycle, and fed ad libitum. All animals were decapitated under anesthesia with ketamine and xylazine in a dose mixture of ketamine $(100 \mathrm{mg} / \mathrm{kg})$ and xylazine $(10 \mathrm{mg} / \mathrm{kg})$, in order to collect the brain samples. The brains were rapidly removed, immediately frozen in liquid nitrogen, and stored at $-80{ }^{\circ} \mathrm{C}$ until analysis. For MDA analysis, brains were homogenized in IKA Ultra-Turrax Tube Drive and were subsequently divided in equal quantities. Afterward, $1 \mathrm{~g}$ of brain sample was spiked with $10 \mu \mathrm{L}$ of working solution, and then PBS was added in a three times higher volume than the sample volume. Samples were vigorously vortexed for $1 \mathrm{~min}$, and immediately after, samples were centrifuged $(10,000 \times g$ for $10 \mathrm{~min})$. After centrifugation, acetonitrile (ACN) was added for protein precipitation $(1: 3, v / v)$. The samples were centrifuged $(10,000 \times g$ for $10 \mathrm{~min})$ and the collected supernatant was diluted with pure water $(1: 1, v / v)$. A volume of $600 \mu \mathrm{L}$ TBA $(4 \mathrm{mg} / \mathrm{mL})$ and $1000 \mu \mathrm{L}$ sulfuric acid $(2.66 \mu \mathrm{L} / \mathrm{mL})$ were added to $400 \mu \mathrm{L}$ sample, followed by heating at $100{ }^{\circ} \mathrm{C}$ for $60 \mathrm{~min}$ in TS-100C, Thermo-Shaker (BioSan, Riga, Latvia). After heating, the samples were transferred in HPLC vials and analyzed shortly after the derivatization reaction.

\subsection{Instrumentation}

Liquid chromatography analysis was performed on a Merck HPLC system: quarternary pump Merck Hitachi L-7100, auto sampler Merck Hitachi L-7200, column thermostat Merck Hitachi L-7360, DAD Merck Hitachi L-7455, interface Merck Hitachi L-7000, solvent degaser Merck Hitachi L-7612, software D-7000 HSM-Manager using Supelcosil LC-18 (3 $\mu \mathrm{m})$ SUPELCO Column $3.3 \mathrm{~cm} \times 4.6 \mathrm{~mm}$, and Supelco Column Saver $0.5 \mu \mathrm{m}$ filter.

\subsection{Method Validation}

In the present study, the validation method was performed in accordance with the regulatory guidelines (FDA 2018). Chosen validation parameters were linearity, selectivity, accuracy, precision, lower limit of quantification (LLOQ), stability, and robustness.

\subsection{Study Application}

In addition, in order to demonstrate the applicability of analytical methods, a study of chronic CNS toxicity was performed on 40 rodents (rats), which were randomly divided 
into 4 groups comprising 10 rats each (Control, Haloperidol, Metformin, and Haloperidol + Metformin). The treatment consisted of distilled water, haloperidol $2 \mathrm{mg} / \mathrm{kg}$ metformin $500 \mathrm{mg} / \mathrm{kg}$, and haloperidol $2 \mathrm{mg} / \mathrm{kg}$ + metformin $500 \mathrm{mg} / \mathrm{kg}$ in a volume of $1 \mathrm{~mL} / \mathrm{kg}$ for 40 days, administered through an oral feeding cannula. At the end of the study, all the rodents were decapitated under anesthesia with ketamine and xylazine in a dose mixture of ketamine $(100 \mathrm{mg} / \mathrm{kg})$ and xylazine $(10 \mathrm{mg} / \mathrm{kg})$, in order to collect the brain samples. The brains were removed, frozen in liquid nitrogen, stored at $-80^{\circ} \mathrm{C}$, and afterward, were analyzed with the method presented in this study.

\subsection{Ethical Considerations}

All procedures were conducted in compliance with all experimental procedures in accordance with European Directive 2010/63/EU and was approved by the Ethics Committee for Scientific Research of the George Emil Palade University of Medicine, Pharmacy, Science and Technology of Târgu Mureș (approval no. 533/2019) and by the National Sanitary Veterinary and Food Safety Authority (approval no. 42/2020).

\section{Conclusions}

Analytical curves for MDA in the brain were linear for the concentration range of $0.2-20 \mu \mathrm{g} / \mathrm{g}$, with a regression coefficient of $\mathrm{r}^{2}=0.998$. This validation method demonstrates good accuracy and precision in accordance with regulatory guidelines [23]. According to these, the accuracy must comprise the $\pm 15 \%$ interval and the precision must be $\leq 15 \%$. Regarding LLOQ, accuracy must comprise the interval of $\pm 20 \%$ and the precision must be $\leq 20 \%$.

The method is suitable for MDA quantification from a rodent's brain and in studies that aim for the measurement and estimation of oxidative stress in different treatments and induced pathologies. Unlike the classic spectrophotometric methods [24,25], this method is superior in terms of sensitivity and specificity; the interferences of other compounds capable of absorption at $532 \mathrm{~nm}$ in VIS is avoided. Moreover, this method is simple and cost-effective; it does not imply the multiple steps of preparation for analytical extraction that may lead to interactions. Instead, a derivatization reaction is proposed.

Author Contributions: Data collection-G.J., conceptualization-G.J., E.F., and M.D.C.; investigationG.J., E.F., M.D.C., A.M., M.-G.B., and C.M.R.; writing—original draft preparation, G.J.; writingreview and editing, G.J., B.-E.Ö., C.E.V., A.T.-V., and M.T.D.; visualization, G.J., B.-E.Ö., C.E.V., and A.T.-V.; funding acquisition, G.J. All authors have read and agreed to the published version of the manuscript.

Funding: This work was supported by the George Emil Palade University of Medicine, Pharmacy, Science, and Technology of Târgu Mureș, research grant number 293/4/14.01.2020.

Institutional Review Board Statement: The study was conducted according to the guidelines of the Declaration of Helsinki, and approved by the Ethics Committee of Scientific Research of the George Emil Palade University of Medicine, Pharmacy, Science and Technology of Târgu Mureș (approval no. 533/2019) and by the National Sanitary Veterinary and Food Safety Authority (approval no. 42/2020).

Data Availability Statement: The datasets that support the findings of this study are available from the corresponding authors upon reasonable request.

Acknowledgments: This work was supported by the George Emil Palade University of Medicine, Pharmacy, Science, and Technology of Târgu Mureș, research grant number 293/4/14.01.2020.

Conflicts of Interest: The authors declare no financial or other conflict of interest.

Sample Availability: Samples of the compounds are not available from the authors. 


\section{References}

1. Nuhu, F.; Bhandari, S. Oxidative Stress and Cardiovascular Complications in Chronic Kidney Disease, the Impact of Anaemia. Pharmaceuticals 2018, 11, 103. [CrossRef] [PubMed]

2. Nuhu, F.; Seymour, A.M.; Bhandari, S. Impact of Intravenous Iron on Oxidative Stress and Mitochondrial Function in Experimental Chronic Kidney Disease. Antioxidants 2019, 8, 498. [CrossRef]

3. Araújo, V.B.; de Melo, A.N.; de Souza, N.T.; da Silva, V.M.; Castro-Gomez, R.H.; Silva, A.S.; de Souza, E.L.; Magnani, M. Oral Intake of Carboxymethyl-Glucan (CM-G) from Yeast (Saccharomyces uvarum) Reduces Malondialdehyde Levels in Healthy Men. Molecules 2015, 20, 14950-14958. [CrossRef]

4. Zelber-Sagi, S.; Ivancovsky-Wajcman, D.; Fliss-Isakov, N.; Hahn, M.; Webb, M.; Shibolet, O.; Kariv, R.; Tirosh, O. Serum Malondialdehyde is Associated with Non-Alcoholic Fatty Liver and Related Liver Damage Differentially in Men and Women. Antioxidants 2020, 9, 578. [CrossRef] [PubMed]

5. Barrera, G.; Pizzimenti, S.; Daga, M.; Dianzani, C.; Arcaro, A.; Cetrangolo, G.P.; Giordano, G.; Cucci, M.A.; Graf, M.; Gentile, F. Lipid Peroxidation-Derived Aldehydes, 4-Hydroxynonenal and Malondialdehyde in Aging-Related Disorders. Antioxidants 2018, 7, 102. [CrossRef]

6. Piastra, M.; Caresta, E.; Massimi, L.; Picconi, E.; Luca, E.; Morena, T.C.; Conti, G.; Eaton, S. Lipid Peroxidation and Antioxidant Consumption as Early Markers of Neurosurgery-Related Brain Injury in Children. Neurocrit. Care. 2020, 33, 124-131. [CrossRef] [PubMed]

7. Reitznerová, A.; Šuleková, M.; Nagy, J.; Marcinčák, S.; Semjon, B.; Čertík, M.; Klempová, T. Lipid Peroxidation Process in Meat and Meat Products: A Comparison Study of Malondialdehyde Determination between Modified 2-Thiobarbituric Acid Spectrophotometric Method and Reverse-Phase High-Performance Liquid Chromatography. Molecules 2017, 22, 1988. [CrossRef]

8. Isola, G.; Polizzi, A.; Santonocito, S.; Alibrandi, A.; Ferlito, S. Expression of Salivary and Serum Malondialdehyde and Lipid Profile of Patients with Periodontitis and Coronary Heart Disease. Int. J. Mol. Sci. 2019, 20, 6061. [CrossRef]

9. Lefevre, G.; Bonneau, C.; Rahma, S.; Chanu, B.; Brault, D.; Couderc, R.; Etienne, J. Determination of plasma protein-bound malondialdehyde by derivative spectrophotometry. Eur. J. Clin. Chem. Clin. Biochem. 1996, 34, 631-636. [CrossRef]

10. Gülçin, İ. Antioxidant activity of food constituents: An overview. Arch. Toxicol. 2012, 86, 345-391. [CrossRef]

11. Okolie, N.P.; Okubo, O.T. A Comparative Study of Malondialdehyde Contents of Some Meat and Fish Samples Processed by Different Methods. J. Pharm. Sci. Innovation 2013, 2, 26-29. [CrossRef]

12. Praticò, D.; Delanty, N. Oxidative injury in diseases of the central nervous system: Focus on Alzheimer's disease. Am. J. Med. 2000, 109, 577-585. [CrossRef]

13. Ou, J.J.; Zhang, Y.; Montine, T.J. In vivo assessment of lipid peroxidation products associated with age-related neurodegenerative diseases. Exp. Neurol. 2002, 175, 363-369. [CrossRef]

14. Wang, X.; Wang, W.; Li, L.; Perry, G.; Lee, H.G.; Zhu, X. Oxidative stress and mitochondrial dysfunction in Alzheimer's disease. Biochim. Biophys. Acta. 2014, 1842, 1240-1247. [CrossRef]

15. Wei, Z.; Li, X.; Li, X.; Liu, Q.; Cheng, Y. Oxidative Stress in Parkinson's Disease: A Systematic Review and Meta-Analysis. Front. Mol. Neurosci. 2018, 11, 236. [CrossRef]

16. Fitzmaurice, P.S.; Tong, J.; Yazdanpanah, M.; Liu, P.P.; Kalasinsky, K.S.; Kish, S.J. Levels of 4-hydroxynonenal and malondialdehyde are increased in brain of human chronic users of methamphetamine. J. Pharmacol. Exp. Ther. 2006, 319, 703-709. [CrossRef] [PubMed]

17. Mateos, R.; Lecumberri, E.; Ramos, S.; Goya, L.; Bravo, L. Determination of malondialdehyde (MDA) by high-performance liquid chromatography in serum and liver as a biomarker for oxidative stress. Application to a rat model for hypercholesterolemia and evaluation of the effect of diets rich in phenolic antioxidants from fruits. J. Chromatogr. B. Analyt. Technol. Biomed. Life. Sci. 2005, 827, 76-82. [CrossRef] [PubMed]

18. Khoubnasabjafari, M.; Ansarin, K.; Jouyban, A. Reliability of malondialdehyde as a biomarker of oxidative stress in psychological disorders. Bioimpacts 2015, 5, 123-127. [CrossRef]

19. Sauce, R.; de Oliveira Pinto, C.A.S.; Ayala-Jara, C.; Prieto, Z.A.; Velasco, M.V.R.; Baby, A.R. Preliminary Protocol Development of a HPLC-TBARS-EVSC (Ex Vivo Stratum Corneum) Assay for Skin Research: Application in a Sunscreen System. Scientia. Pharmaceutica. 2021, 89, 17. [CrossRef]

20. Fogarasi, E.; Croitoru, M.D.; Fülöp, I.; Nemes-Nagy, E.; Tripon, R.G.; Simon-Szabo, Z.; Muntean, D.L. Malondialdehyde levels can be measured in serum and saliva by using a fast HPLC method with visible detection. Rev. Română Med. Lab. 2016, 24, 319-326. [CrossRef]

21. Tsaknis, J.; Lalas, S.; Evmorfopoulos, E. Determination of malondialdehyde in traditional fish products by HPLC. Analyst 1999, 124, 843-845. [CrossRef]

22. Siddique, Y.H.; Ara, G.; Afzal, M. Estimation of lipid peroxidation induced by hydrogen peroxide in cultured human lymphocytes. Dose-Response 2012, 10, 1-10. [CrossRef] [PubMed]

23. FDA. Guidance for Industry: Bioanalytical Method Validation. 2018. Available online: https://www.fda.gov/downloads/drugs/ guidances/ucm070107.Pdf (accessed on 5 July 2021). 
24. Adedeji, H.A.; Ishola, I.O; Adeyemi, O.O. Novel action of metformin in the prevention of haloperidol-induced catalepsy in mice: Potential in the treatment of Parkinson's disease? Prog. Neuropsychopharmacol. Biol. Psychiatry 2014, 48, 245-251. [CrossRef] [PubMed]

25. Almeida, P.M.D.; Kamath, S.U.; Shenoy, P.R.; Bernhardt, L.K.; Kishore, A.; Rai, K.S. Persistent attenuation of brain oxidative stress through aging in perinatal maternal separated rat pups supplemented with choline and docosahexaenoic acid or Clitoria ternatea aqueous root extract. Folia Neuropathol. 2018, 56, 206-214. [CrossRef] [PubMed] 